\title{
Determinant of Under-Five Child Mortality in Ethiopia
}

\section{Dechasa Bedada}

Department of Statistics, College of Natural Science, Jimma University, Jimma, Ethiopia

\section{Email address:}

decheebe@gmail.com

\section{To cite this article:}

Dechasa Bedada. Determinant of Under-Five Child Mortality in Ethiopia. American Journal of Theoretical and Applied Statistics. Vol. 6, No. 4, 2017, pp. 198-204. doi: 10.11648/j.ajtas.20170604.15

Received: March 1, 2017; Accepted: March 27, 2017; Published: July 7, 2017

\begin{abstract}
Many countries are not on track to complete UNICEF's Millennium Development Goals (MDGs) target of a twothirds reduction in the rate of child mortality by 2015. This paper examines determinants of under-five mortality in Ethiopia. The study utilizes the data extracted from the 2011 Ethiopia demographic and health survey. Multivariate logistic analysis reflects that sex of the child, family size, education level of mother, age at first birth of mother, breast-feeding; using contraceptive method and region of child have significant influence on under-five child mortality in Ethiopia. The proximate determinants are found to have stronger influence on under-five mortality than the socioeconomic factors considered in the study do.
\end{abstract}

Keywords: Under Five Mortality, Logistic Regression Model, Determinant

\section{Introduction}

Under-five child mortality is a factor that can be associated with the safety of a population and is used as one of the improvement indicators of health, socioeconomic status, and life quality of a given population, as measured by life expectancy. Improvements in child survival have been one of the major targets of development programmers during the past three decades, and child mortality rates have shown substantial and consistent declines in all regions of the world since 1960 [1]. Most countries of the world have agreed to the Millennium Development Goal (MDG) of reducing child mortality by two-thirds by 2015 . The United Nations (UN) prepared a report in 2001 on the progress towards childsurvival goals [2]. In recent years however, these positive trends have declined, and even reversed in many sub-Saharan African countries while they have continued to improve in other regions [3].

Despite steep challenges, a number of countries with very high rates of child mortality reported in 1990 have defied the odds, showing that progress for all children is within our grasp. Bangladesh and Liberia, for example, have achieved reductions in under-five mortality of at least two thirds since 1990. Ethiopia, Madagascar, Malawi, Niger, and Rwanda in sub-Saharan Africa, and Bhutan and Nepal in Southern Asia, have seen reductions of at least 60 percent [4].
A number of studies indicated that the mortality rate especially the mortality rate of children under five in Ethiopia has been declining [5 and 6]. The critical forces for this decline are many. The declining of the role of agriculture in the national economy, the increase of urbanization and the launching of globalization which has accelerated the economic performance of the country and significantly changed the trend of mortality rates particularly the mortality rate of children under five [7].

The current mortality rate of children under-five is still high in comparison to the expectation of the Millennium Development Goals (MDGs). Reducing the mortality rate of children to 67 per 1000 live births was internationally adopted at the 1990 world summit for children. At this time the level of infant and child mortality rate were among vital indicators of the levels of socioeconomic progress of countries. Children are at greater risk of dying before age five if they are born in rural areas, poor households, or to a mother denied basic education [4].

Similarly, like other developing countries, there is a significant difference in mortality rates among urban and rural residents of Ethiopia. According to the 2005 Ethiopian Demography Health Survey (EDHS) report, infant, child and under-five mortality were lowest 66, 32 and 35 per 1000 live births respectively in urban areas while 81,40 and 41 per 1000 live births in rural areas, respectively. The urban-rural variation is even more pronounced in the mortality of 
children under five. The regional variations in infant and child mortality rates are also pronounced in Ethiopia [8].

Taken separately, maternal education, age, marital status and presence of co-wives are related with childhood mortality. The relationship of these indicators with women's autonomy, health on the lookout for behavior, and other factors that affect child survival merit further investigation so that interventions could be designed to foster reductions in child mortality by considering the needs and welfare of women including the need for female education, autonomy and socioeconomic well-being [9]. Additionally, the causes of high under-five mortality in resource poor settings are complex and merit concerted efforts to clarify their implications to improve child survival [10].

The world is not yet on track to complete the Millennium Development Goals (MDGs) target of a two-thirds reduction in the rate of child mortality by 2015. Many demographers and scholars believe and recommend the need to conduct indepth studies on the various aspects of infant and child health status in a different demographic, economic, and socialcultural setting. Researchers have already documented the importance of conducting studies on the socioeconomic, demographic, health and environmental determinants of mortality status of children under five in Ethiopia. Understanding the geographic distribution of mortality of children under five is important to policy interventions. Mortality rates in most parts of the sub-Saharan African and Southern Asia countries tend to cluster by area, often identified as high or low-mortality regions [11]. This study tries to assess the major risk factors associated with underfive child mortality in Ethiopia, taking into consideration various health, socioeconomic and environmental factors.

\section{Materials and Methods}

The study was based on the national cross-sectional demographic and health survey (EDHS) conducted in Ethiopia 2011. The EDHS collects nationally-representative data on women of child-bearing age (15-49 years) and their children. The data used for under-five mortality estimation were collected in the birth history section of the Woman's Questionnaire from 16,515 women aged 15-49. The birth history section begins with questions about the respondent's experience with childbearing. These questions are followed by a retrospective birth history, in which each respondent is asked to list each of her births, starting with the first birth. The dependent (response) variable is child survival status. The response was binary: yes or no. As mentioned above, the dependent variables are dichotomous, coded as zero if death has not occurred and coded as 1 if death has occurred (alive $=0$ and dead $=1$ ). Many explanatory variables are used as predictors of under-five child mortality. Broadly, the researcher grouped the variables into three: socioeconomic, biological and maternal, and Environmental health determinants, which contribute to under-five child mortality. Variables that are included in socioeconomic category include place of residence, work status of mother and mother's education level. Variables considered under biological and maternal determinants are age of mother, birth order, and sex of a child. Variables that are considered as elements of environmental health include source of drinking water.

\section{Statistical Methods}

Binary data are the most common form of categorical data and the most popular model for binary data is a logistic regression model [12]. This model allows one to predict outcomes from a set of variables that may be continuous, discrete, dichotomous, or a mix of any of these. Hosmer and Lemeshow have described logistic regression focusing on its theoretical and applied aspect. Logistic regression models the odds of success which is defined as the ratio of the probability of a success to the probability of a failure. Hence, if $p$ is the true success probability the odd of a success is $p /$ (1-p) [13].

\section{Results}

The major demographic and socio-economic characteristics of the respondents with under-five child mortality are presented in Table 1 below. The total number of children covered in the present study is 11654 . Among these, $846(7.26 \%)$ were dead whereas $10808(92.74 \%)$ were alive at the date of the survey.

Table 1. Distribution of Demographic and Socioeconomic Factors on Mortality Status of Children under-Five in Ethiopia.

\begin{tabular}{|c|c|c|c|c|}
\hline \multirow{2}{*}{$\begin{array}{l}\text { Covariates } \\
\text { (Explanatory variables) }\end{array}$} & \multicolumn{4}{|c|}{ Under-five child mortality ( U5CM) status } \\
\hline & Live & Death & Total & $\%$ of U5CM status \\
\hline \multicolumn{5}{|l|}{ Regions } \\
\hline Tigray & 1123 & 79 & 1202 & 6.6 \\
\hline Affar & 1033 & 97 & 1130 & 8.6 \\
\hline Amhara & 1203 & 91 & 1294 & 7 \\
\hline Oromiya & 1637 & 124 & 1761 & 7 \\
\hline Somali & 951 & 76 & 1027 & 7.4 \\
\hline Benishangul-Gumuz & 925 & 95 & 1020 & 9.3 \\
\hline SNNP & 1491 & 123 & 1614 & 7.6 \\
\hline Gambela & 782 & 69 & 851 & 8.1 \\
\hline Harari & 616 & 43 & 659 & 6.5 \\
\hline Addis Ababa & 386 & 14 & 400 & 3.5 \\
\hline Dire Dawa & 661 & 35 & 696 & 5 \\
\hline \multicolumn{5}{|l|}{ Place of Residence } \\
\hline Urban & 1865 & 121 & 1986 & 6.1 \\
\hline Rural & 8943 & 725 & 9668 & 7.5 \\
\hline \multicolumn{5}{|l|}{ Sex of children } \\
\hline Male & 5515 & 472 & 5987 & 7.9 \\
\hline Female & 5293 & 374 & 5667 & 6.6 \\
\hline \multicolumn{5}{|l|}{ Age of mother } \\
\hline $15-19$ & 463 & 51 & 514 & 9.92 \\
\hline $20 \_29$ & 5562 & 420 & 5982 & 7.02 \\
\hline 30- 39 & 3871 & 289 & 4160 & 6.95 \\
\hline $40-49$ & 912 & 86 & 998 & 8.62 \\
\hline Birth order & & & & \\
\hline
\end{tabular}




\begin{tabular}{lllll}
\hline $\begin{array}{l}\text { Covariates } \\
\text { (Explanatory variables) }\end{array}$ & \multicolumn{4}{l}{ Under-five child mortality ( U5CM) status } \\
\hline & Live & Death & Total & \% of U5CM status \\
\hline 1 & 2130 & 173 & 2303 & 7.5 \\
2,3 or 4 & 4820 & 358 & 5178 & 6.9 \\
5 & 3858 & 315 & 4173 & 7.5 \\
Family size & & & & \\
$1-5$ & 4694 & 480 & 5174 & 9.3 \\
$>5$ & 6114 & 366 & 6480 & 5.6 \\
Wealth index & & & & \\
Poor & 5277 & 462 & 5739 & 8.1 \\
Middle & 1738 & 134 & 1872 & 7.2 \\
Rich & 3793 & 250 & 4043 & 6.2 \\
Source of Drinking water & & & & \\
Piped & 2803 & 171 & 2974 & 5.7 \\
Spring & 2861 & 234 & 3095 & 7.6 \\
Tube Well Water and & 5144 & 441 & 5585 & 7.9 \\
others & & & & \\
Educational level & & & & \\
No Education & 7839 & 636 & 8475 & 7.5 \\
Primary & 2500 & 191 & 2691 & 7.1 \\
Secondary & 278 & 14 & 292 & 4.8 \\
Higher & 191 & 5 & 196 & 2.6 \\
Breastfeeding & & & & \\
No & 3367 & 502 & 3869 & 13 \\
Yes & 7441 & 344 & 7785 & 4.4 \\
Age of first birth & & & & \\
$<$ 20 & 6627 & 549 & 7176 & 7.7 \\
>=20 & 4181 & 297 & 4478 & 6.6 \\
Using contraceptive & & & & \\
method & & & & \\
Yes & 2306 & 119 & 2425 & 4.9 \\
No & 8502 & 727 & 9229 & 8.6 \\
\hline & & & & \\
\hline
\end{tabular}

The under-five child mortality rates (U5CM) varied from one region to the other in Ethiopia. For example, the highest percentage of deaths among children under-five was observed in Benishangul-Gumuz (9.3\%) followed by Afar $(8.6 \%)$ while the lowest percentage of deaths was recorded in Addis Ababa (3.5\%) and followed by Dire Dawa (5.0\%). Hence, there appears to be some variation in the proportion of mortality of children under-five in different regions. Across place of residence, a higher death rate $(7.5 \%)$ was recorded in rural areas, when compared to urban areas $(6.1 \%)$. Examining the U5CM by age showed the largest rate was among women $15-19$ years $(9.9 \%)$ and the lowest among women 30 -39 years $(7.0 \%)$ (Table 1$)$.

The U5CM varies by wealth index (household's economic status), sex of children (gender) and breastfeeding. By wealth index, the highest U5CM was observed among children from poor households $(8.1 \%)$ when compared to children residing among rich households (6.2\%). With regard to sex of children, a higher U5CM was observed among male children (7.9\%) compared to female children $(6.6 \%)$ of the same age. Likewise, the U5CM was found to be lower among breastfeeding children (4.4\%) compared to non-breastfeeding children (13.0\%). As maternal education increased the U5CM decreased. The highest U5CM was observed in women who have no education $(7.5 \%)$ as opposed to the lowest percentage of death of under-five child that was recorded for women who have higher education level (2. 6\%) (Table 1).

As shown in table 1 the family size, age of first birth, contraceptive method status, and source of drinking water are the death of under-five child are different in number. Higher U5CM were observed in family size below five (9.3\%) compared to family size less than five, mother's age of first birth less than $20(7.7 \%)$ compared to 20 years or older, noncontraceptive method using households $(8.6 \%)$ compared to households using a contraceptive method, and using tube well and others source of drinking water $(7.9 \%)$ compared to piped and spring.

The logistic regression analysis results obtained by using stepwise inclusion of variables, overall model evaluation, statistical tests of individual predictors and goodness-of-fit statistics are presented. The Initial Log Likelihood function, (-2 Log Likelihood or -2LL) is a statistical measure similar to total sums of squares in regression The statistical significance of individual regression coefficients is tested using the Wald score and chi-square statistic. In this section, we identify the statistically significant predictor variables and determine the direction of relationship with and contribution to the dependent variable.

Female children have a $16 \%$ reduction in the odds of dying before age $5(\mathrm{OR}=0.84 .05)$ compared to male children controlling for other variables in the model. Similarly, children from family size greater than or equal to five have a $43.5 \%$ reduction in the odds of dying before age $5(\mathrm{OR}=$ 0.5646 ) compared to children from family size less than five controlling for other variables in the model.

The odds of dying before age 5decrease as maternal education level increased. The odds of dying before age 5 was 2.1 for children who had a non- educated mother compared to children who had a mother with higher education, while children with a primary educated mother had an $89.1 \%$ increase in the odds of death before age 5 when compared to children with a higher educated mother $(\mathrm{OR}=1.891)$ controlling for other variables in the model.

Children who were breast fed had a $71.2 \%$ reduction in the odds of death before age $5(\mathrm{OR}=0.288)$ compared to children who were not breast fed, controlling for other variables in the model. Children who were from families not using contraceptive method had as $75.4 \%$ increased odds of death before age $5(\mathrm{OR}=1.754)$ compared to children from families using contraceptive methods, controlling for other variables in the model.

Children whose mothers were older at first birth (20 years or older) had a $15.6 \%$ reduction in the odds of deaths before age $5(\mathrm{OR}=0.844)$ compared to children from mothers age of first birth less than 20 years, controlling for other variables in the model.

The odds of death before age 5 were elevated in Amhara $(\mathrm{OR}=2.02), \operatorname{Oromia}(1.97)$, Benishangul- $\operatorname{Gumez}(2.47)$, $\operatorname{SNNP}(2.17)$ and Gambela National Regional State (2.45) compared to in Addis Ababa controlling others variables in the model. 
Table 2. Multivariable Logistic Regression Analysis of Under-five Child Mortality, in Ethiopia, EDHS 2011, (n=11654).

\begin{tabular}{|c|c|c|c|c|c|c|}
\hline \multirow{2}{*}{$\begin{array}{l}\text { Parameter } \\
\text { Intercept }\end{array}$} & \multirow{2}{*}{$\begin{array}{l}\text { Estimate } \\
-3.2141\end{array}$} & \multirow{2}{*}{$\begin{array}{l}\text { Standard error } \\
0.3444\end{array}$} & \multirow{2}{*}{$\begin{array}{l}\text { Pr }>\text { ChiSq } \\
0.000\end{array}$} & \multirow{2}{*}{$\begin{array}{l}\text { OR } \\
-\end{array}$} & \multicolumn{2}{|c|}{ [95\% C. Interval of OR ] } \\
\hline & & & & & - & \\
\hline \multicolumn{7}{|l|}{ Sex of Child } \\
\hline \multicolumn{7}{|l|}{ Male (ref.) } \\
\hline Female & -0.1737 & 0.0734 & 0.018 & 0.8405 & 0.7279 & 0.9705 \\
\hline \multicolumn{7}{|l|}{ Family size } \\
\hline \multicolumn{7}{|l|}{$1-5$ (ref.) } \\
\hline$>5$ & -0.5715 & 0.0748 & 0.000 & 0.5647 & 0.4877 & 0.6538 \\
\hline \multicolumn{7}{|l|}{ Education level } \\
\hline \multicolumn{7}{|l|}{ Higher (ref.) } \\
\hline No Education & 0.7448 & 0.2430 & 0.002 & 2.1060 & 1.3081 & 3.3906 \\
\hline Primary & 0.6369 & 0.2481 & 0.010 & 1.8906 & 1.1626 & 3.0747 \\
\hline Secondary & 0.3272 & 0.3617 & 0.366 & 1.3871 & 0.6827 & 2.8182 \\
\hline \multicolumn{7}{|l|}{ Breast feeding } \\
\hline \multicolumn{7}{|l|}{ No (ref.) } \\
\hline Yes & -1.2459 & 0.0750 & 0.000 & 0.2877 & 0.2483 & 0.3333 \\
\hline \multicolumn{7}{|c|}{ Use of Contraceptive } \\
\hline \multicolumn{7}{|c|}{ Yes (ref.) } \\
\hline No & 0.5621 & 0.1081 & 0.000 & 1.7543 & 1.4192 & 2.1684 \\
\hline \multicolumn{7}{|l|}{ Age of first Birth } \\
\hline$>=20$ & -0.1693 & 0.0774 & 0.029 & 0.8442 & 0.7254 & 0.9825 \\
\hline \multicolumn{7}{|l|}{ Region } \\
\hline \multicolumn{7}{|l|}{ A. Ababa(ref.) } \\
\hline Tigray & 0.4559 & 0.3066 & 0.137 & 1.5776 & 0.8649 & 2.8775 \\
\hline Affar & 0.5551 & 0.3068 & 0.070 & 1.7422 & 0.9548 & 3.1787 \\
\hline Amhara & 0.7040 & 0.3057 & 0.021 & 2.0218 & 1.1106 & 3.6805 \\
\hline Oromia & 0.6800 & 0.2993 & 0.023 & 1.9739 & 1.0979 & 3.5491 \\
\hline Somali & 0.4996 & 0.3118 & 0.109 & 1.6481 & 0.8946 & 3.0364 \\
\hline Benishangul-G & 0.9046 & 0.3057 & 0.003 & 2.4709 & 1.3572 & 4.4986 \\
\hline SNNP & 0.7732 & 0.2994 & 0.010 & 2.1667 & 1.2048 & 3.8964 \\
\hline Gambela & 0.8939 & 0.3100 & 0.004 & 2.4446 & 1.3314 & 4.4885 \\
\hline Harari & 0.5434 & 0.3234 & 0.093 & 1.7218 & 0.91343 & 3.2455 \\
\hline Dire Dawa & 0.1533 & 0.3328 & 0.645 & 1.1656 & 0.60713 & 2.2396 \\
\hline
\end{tabular}

Ref. $=$ reference

As shown in the above Table 2, Region, breastfeeding, sex of children, family size, mother"s education level, contraceptive method, and age of first birth of mothers were found to be significant predictors of under-five children mortality at $5 \%$ level of significance. But, secondary education level, Tigray region, Affar region, Somali region, Harari region and Dire dawa are not significant when compare to Addis Ababa. Thus, the estimated model is given by:

$$
\begin{aligned}
& \log i t(\hat{p})=-3.2141-0.1737 \text { Sexch }_{\text {female }}-0.5715 F_{\text {.size }}+0.7448 \text { Educ }_{\text {noeduc }} \\
& +0.6369 \text { Educ }_{\text {Prim }}+0.3272 \text { Educ }_{\text {Seco }}-1.2459 B r . \text { feed }_{\text {Yes }}
\end{aligned}
$$

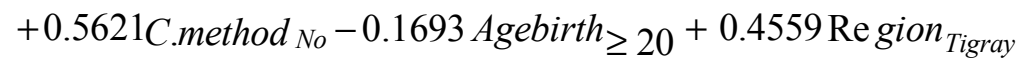

$$
\begin{aligned}
& +0.0115 \operatorname{Re}_{\text {gion }_{\text {Affar }}}+\ldots .+0.5434{\text { Re } \text { gion }_{\text {Harari }}}+0.1533 \text { Re }_{\text {gion }} \text { Dire.Dawa }
\end{aligned}
$$

The value of where: ${ }_{p}$ = predicted probability of under-

five child mortality, $\beta_{0}=$ constant, Sexchi $=$ Sex of child $\mathrm{i}$, F.sizej = Family size j, Educm = Education level $\mathrm{m}$, Agebirthl $=$ Age of first birth of mother 1, Br.feedr $=$ Breast feeding r, C.methodn $=$ Mother use contraceptive method $n$ and Regionk $=$ children's region $\mathrm{k}$.
Table 3. Test of Significance of the Relationship between the Dependent and Independent Variables.

\begin{tabular}{llll}
\hline \multicolumn{4}{l}{ Testing Global Null Hypothesis: BETA $=\mathbf{0}$} \\
\hline Test & Chi-Square & DF & Pr $>$ ChiSq \\
\hline Likelihood Ratio & 414.4425 & 18 & $<0.0001$ \\
Score & 426.0795 & 18 & $<0.0001$ \\
Wald & 390.8171 & 18 & $<0.0001$ \\
\hline
\end{tabular}

In Table 3 the model Chi-Square value of 414.4425 has a 
P-Value of less than 0.001. Similarly, score and Wald tests also have P-values less than 0.05 and are significant. All three tests yield similar conclusions, that is, the final model with explanatory variables was more effective than the null model. So, we conclude that there is a significant relationship between the dependent variable and the set of independent variables.

The Hosmer-Lemeshow goodness of fit test was employed and the result is presented in Table 4 a good model fit is indicated by a none-significant chi-square value.

Table 4. Test of Significance of Hosmer-Lemeshow Goodness of Fit Statistics.

\begin{tabular}{lcl}
\hline Hosmer and Lemeshow Goodness-of-Fit Test & \\
\hline Chi-Square & DF & Pr $>$ ChiSq \\
7.2878 & 8 & 0.5059 \\
\hline
\end{tabular}

The better model fit is indicated by a smaller difference in the observed and predicted classification. The HosmerLemeshow Goodness-of-fit test tests the hypotheses:

Ho: the model is a good fit, vs.

Ha: the model is not a good fit

Since the P-value in Table 4 P-value $=0.5059$ is larger than 0.05 , we do not reject the null hypothesis, and we conclude that the model is a good fit.

\section{Discussion}

This study has indicated that some of the demographic and socio-economic variables considered have significant influence on the under-five children mortality rate. Sex of the child, family size, education level of mother, age of mother, breast-feeding and the use of contraceptive method and region of child were found to be among the determinants of under-five child mortality in Ethiopia.

According to the results, mother's education level is an important socio-economic predictor of under-five child mortality, that is, mortality rate decreases with increase in mother's education level. Many studies showed that the higher the level of maternal education, the lower the infant and child mortality. Caldwell study provided three explanations for the phenomenon: mothers that are more educated become less fatalistic about their children' illnesses, they are more capable of manipulating available health facilities and personnel and they greatly change the traditional balance of familial relationships with profound effects on childcare [14]. In addition to these, they are more likely to have received antenatal care to give birth with some medical attendance, and to take their children at some time to see a physician. In this study, even after controlling for other variables, education of mother remained significant in the regression equations. This finding is consistent with [15].

Maternal education is a major determinant of child survival, influencing care seeking, morbidity and nutritional status. Only $34 \%$ of adult Ethiopian women are educated, compared with $49 \%$ of men, and $20 \%$ fewer girls than boys enroll for primary school. The U5MR for children whose mothers have no schooling is $121 \%$ higher than those whose mothers have at least a secondary education [16].

The risk of death of under-five female children was significantly different from that of male children. [1]. The mortality rate of boys appears to be more sensitive to parents' education levels than the mortality rate of girls. A high education level of the father is particularly protective for boys. We have argued that gender-specific patterns of social interactions within the family could be a part of the explanation [17].

Household wealth in Ethiopia was a significant determinant of under-five children mortality. According to our finding, households with greater wealth were less likely to have underfive children deaths compared with children of the poor households [15 and 18]. Income of the households is one of the commonly identified social determinants of health. Previous study has indicated that income and under five mortality had negative statistical association [19]. Even countries with higher national income were associated with lower under-five mortality rates [20]. Similarly, in this study a significant reduction in risk of under-five mortality was observed among births to mothers residing in richest households. Even though, basic health services are free in Ethiopia, other opportunistic costs and in case of severe health problems; catastrophic costs cannot be affordable to less income households for advanced and better health services.

The finding of the study showed that the odds of death of under-five children from mothers using contraceptive is significantly less than children from non- contraceptive methods using mothers. The study also showed that the odds of death before the age five among children whose mother's age at first birth is greater than or equal to 20 years was significantly less than among children whose mother's age at first birth is less than 20 years. This finding is consistent with result of [21 and 22]. Sub-Saharan Africa countries are characterized by low contraceptive prevalence. Low total fertility rate (TFR) can be associated with a high contraceptive prevalence rate. Countries like Kenya with low mean ages at first intercourse, marriage and birth have a lower total fertility rate (TFR) (less than 6) because its contraceptive prevalence rate is higher than 30 percent. It seems that countries with a prevalence rate of more than 40 percent have a total fertility rate (TFR) of less than 5 . This is true even for other selected developing countries analyzed in this study [23].

Concerning the regional disparity in under-five child mortality, the results of study showed that children who live in Amhara, Benishangul-gumaz, Gambela, Oromia and SNNP National Regional States are at a higher risk of death than children who live in Addis Ababa. Like most other aspects of health care in Ethiopia, maternal and child health services are not well developed. In Ethiopia wide regional differentials in infant and under-five mortality are observed. There are rural-urban differences in access to services and in health care outcomes. Differences between the regional states are also significant. Roads are not well developed and transportation problems are severe, especially during the rainy season and also in remote area. The diversity of 
climate, terrain, and socio-economic environments are impacting health conditions and outcomes. Inadequate and substandard health coverage is of particular concern in rural Ethiopia and developing region, where access to modern medicine is limited in those areas. When compare those areas with Addis Ababa with respect to health care access, facilities, health service, resource and others are limited. Those factors are having their contribution to regional disparity in under-five child mortality in Ethiopia. [24].

\section{Conclusion}

The results of this study suggested the need to use individual level (child) and region level disparities in the likelihood of under-five child mortality. Interventions to reduce the U5CM should begin with exploring the factors that drive regional differences as well as other common factors that affect the under-five mortality rate. This study found evidence that verify some demographic and socioeconomic variables considered in this study have a significant influence on the under-five child mortality. Sex of the child, family size, education level of mother, age at first birth of mother, breast-feeding and the use of contraceptive method and regions of children were found to be determinant of under-five child mortality in Ethiopia.

A limitation of this study is the retrospective nature of the DHS data. The data is large, nationally representative sample of all deaths based on household interviews with families. The study results reflect the whole of the selected regions. Despite these strengths, a number of weaknesses were also present in this study. The birth history section of 2011 EDHS begins with questions about the respondent's experience with childbearing. Hence, 2011 EDHS was subject to possible data collection errors (e.g., only surviving women aged 1549 were interviewed); therefore, no data were available for children of women who had died. Respondents were likely to forget events that occurred in the past. This introduces recall bias in the reporting of events over the preceding 10 year period. In addition, the place of residence of some respondents at the time of the survey may have changed over the period from the date of birth of the child.

The researcher considers factors that related to mother of child that affect under-five child mortality. This study is better to include factors that related to father of child which can determine under-five child mortality in Ethiopia. Thus possible extensions for further research include the use of models that include interaction effects factors in addition to main effect factors explanatory variables to under-five child mortality for the logistic regression model. More advanced methods like multilevel model are also better options when analyzing large datasets and identifying more variation among the regions.

\section{Acknowledgements}

I would like to thank Jimma University for giving me all necessary material when I do this research and all my staff department of statistics for invaluable comments, suggestions, and patience during the entire time of the research.

\section{References}

[1] Hill. K. and Upchurch D. M. Gender differences in child health. Evidence from the demographic and health surveys. Population and Development Review, 1995; 21(1):127151.

[2] UNICEF. The state of the world's children. New York, 1999.

[3] Ahmed OB, Lopez AD. and Inoue M. The decline in child mortality. Bull World Health Organ, 2000,78: 1175-1191.

[4] MDGs Report. Assessing progress in Africa forward the Millennium Development Goals(MDGs), 2013.

[5] Susuman, A. S. Child Mortality Rate in Ethiopia. Iranian Journal of Public Health, 2012; 41(3), 9-19.

[6] Ayele, D. G., \& Zewotir, T. T.. Comparison of under-five mortality for 2000, 2005 and 2011 surveys in Ethiopia. BMC public health, 2016; 16(1), 930.

[7] Kenny, A. and Kenny, C. Life, liberty and the pursuit of utility: Happiness in Philosophical and economic Thought London: Imprint Academic, 2006.

[8] Desta, M. Infant and Child Mortality in Ethiopia The role of Socioeconomic, Demographic and Biological factors In the previous five years period of 2000 and 2005. lund university, 2011.

[9] Kanmiki, E. W., Bawah, A. A., Agorinya, I., Achana, F. S., Awoonor-Williams, J. K., Oduro, A. R.,... \& Akazili, J. Socioeconomic and demographic determinants of under-five mortality in rural northern Ghana. BMC international health and human rights, 2013; 14, 24-24.

[10] Kanmiki, E. W., Bawah, A. A., Agorinya, I., Achana, F. S., Awoonor-Williams, J. K., Oduro, A. R.,... \& Akazili, J. Socioeconomic and demographic determinants of under-five mortality in rural northern Ghana. BMC international health and human rights, 2014; 14(1), 1.

[11] WHO. The world health report 2005 make every mother and child count: Geneve. World Health Organization, 2005.

[12] Agresti A. An Introduction to Categorical Data analysis. 2nd Ed. Canada: John Wiley and Sons ISBN 978-0-471-22618-5, 200.

[13] Hosmer, W. D. and Lemeshow, S. (2000), Applied Logistic Regression. 2nd Ed., John Wiley and Sons, New York, 2000.

[14] Caldwell, C. J. The Soft Underbelly of Development: Demographic Transition in Conditions of Limited Economic Change, Comments, Proceedings of the World Bank Annual Conference on Development Economics. Washington DC. The World Bank. 1991; Page. 207-253.

[15] Belaineh, G., Amare, D. and Fasil, T. Determinants of underfive mortality in Gilgel Gibe Field Research Center, Southwest Ethiopia, Ethiop. J. Health Dev., 2007; 21(2):117124. 
[16] WHO. WHO vaccine-preventable diseases: monitoring system -2007 global summary, Geneva, World Health Organization, 2007.

[17] Le Pham, T., Kooreman, P., Koning, R. H., \& Wiersma, D. Gender patterns in Vietnam's child mortality. Journal of Population Economics, 2013; 26(1), 303-322.

[18] Kimani, J. and Ettarh, R. R. Determinants of under-five mortality in rural and urban Kenya. African Population and Health Research Center. Nairobi. Rural and Remote Health, 2012; 12: 1812.

[19] Diddy, A. Regional inequalities in under-5 mortality in Nigeria: A population-based analysis of individual and community-level determinants. Antai Population Health Metrics, 2011; 9, 6.

[20] Tanja, H., Anton, K., Caspar, L. and Johan, M. Determinants of under-5 mortality among the poor and the rich: A cross- national analysis of 43 developing countries. International Journal of Epidemiology, 2005; 34, 1257-1265.

[21] Mondal, N. I., Hossain, K. and Ali, K. (2009). Factors Influencing Infant and Child Mortality: A Case Study of Rajshahi District. Bangladesh. J. Hum Ecol. 2009; 26(1): 3139.

[22] Aguirre P. G. Child mortality and reproductive patters in urban Bolivia. University of Wisconsin-Madison. Center for Demography and Ecology. 1995; CDE working paper No. 95-28.

[23] Dobratz, S. Age at First Birth, Fertility, and Contraception in Tanzania. Tanzania, 1998.

[24] Aynalem A. Health Institutions and Services. www.EthioDemography And Health.Org, 2014. 